\title{
EL DERECHO DE TENUTA COMO GARANTÍA DE LA RESTITUCIÓN DOTAL EN EL DERECHO FORAL VALENCIANO.
}

por

\section{$\mathbf{M}^{\mathbf{a}}$. Dolores Guillớ ALIAGA}

Universitat de València

RESUMEN: El derecho de «tenuta* nace, una vez transcurrido el año de luto — «any de plorv-, cuando los berederos del marido no ban restituido a la mujer su dote 0 "exovarm, ni le han pagado el xcreix" o aumento dotal. La mujer pasa, entonces, a poseer todos los bienes del difunto con la facultad de bacer suyos los frutos por imperativo legal. Se trata de un derecho de garantia, pues su finalidad es asegurar la restitución del rexovaro. La atenutas se extingue cuando los berederos del marido restituyen la dote y pagan el aumento dotal, de mado que si éstos, extinguido el matrimonio, lo bacen inmediatamente, el derecho no llega a tener efecto. También puede perderlo la mujer si prolonga maliciosa o innecesariamente su disfrute. Esta facultad de poseer se da sobre los bienes libres; pero, en defecto de éstos, o si son insuficienter, también puede darse sobre los vinculados por un ascendiente.

PALABRAS ClaVE: Derecho de tenuta. Exovar. Creix. Derecho de garantía.

ABSTRACT: The right of «tenuta» ariser once the year of mourning — «any de plorn- bas elapsed where the beirs to the deceased husband bave neither returned the dowry - exovarn - to the surviving wife nor paid the dotal increase $\longrightarrow$ creix widow then obtains possession of the deseased husband's property and is entitled to its usufruct by operation of law. Its purpose is to att as a guarantee, since it aims to secure the return of the aexovar». The atenutan ceases when the beirs return the dowry and pay the dotal increase, which means that if they do so immediately after the marriage bas ceased, the right does not take effect. The widow may also be deprived of the atenuta* if she retains it maliciously or for an unnecessarily long period. This right of porsession covers freebold property; but if there is none or if it is insufficient, it can also cover property entailed by a relative in the ascendant line.

KEY WORDS: Right of «tenuta». «Exovar». «Creix». Guarantee. 
El sistema matrimonial del Reino de Valencia en la época foral, en general, es el de separación de bienes, suavizado por el sistema dotal ya que los bienes privativos o parafernales de la mujer no contribuyen al sostenimiento de las cargas matrimoniales, siendo las instituciones jurídicas básicas dentro de este sistema la dote o exovar y el creix ${ }^{1}$. No obstante, los contrayentes pueden establecer cualquier pacto en sus capitulaciones matrimoniales siempre que no sean contrarios a la ley. Por dote hay que entender la aportación que la mujer u otro por ella da al marido por razón de matrimonio para ayudarle al sostenimiento de las cargas familiares con los frutos obtenidos de la misma ${ }^{2}$. Junto a ésta, se halla el creix $x^{3}$, cuya existencia está condicionada a que haya dote y a que la mujer sea doncella, estando prohibido el que se constituya a la viuda. Su importe es siempre la mitad de la dote aportada, siendo necesario que se dé siempre esta proporción.

El exovar, por su naturaleza, es restituible, gozando de todas las garantías para su devolución. Debe devolverse cuando el matrimonio se disuelva por muerte de alguno de los cónyuges o por separación de éstos. Aunque, también, se permite la restitución, constante el matrimonio, en los casos de empobrecimiento o mal uso de su fortuna por parte del marido.

Disuelto el matrimonio por muerte del cónyuge, la mujer no puede pedir la restitución del exovar ni el pago del creix hasta que no haya transcurrido un año, el any de plor, que es el plazo que exigen los fueros para la devolución y pago, a no ser que los herederos renuncien al mismo, exceptuando los bienes inmuebles inestimados que deben restituirse inmediatamente tras la disolución. Este año de luto se configura, en el derecho valenciano, como un derecho de alimentos ya que, durante el mismo, los herederos del esposo premuerto están obligados a prestar alimentos y ropa de luto a la viuda pues debe ser considerada como si todavía viviese el marido. La razón de la existencia de este año es por el tiempo que se concede a los herederos de aquél para que restituyan la dote y paguen el creix.

Transcurrido el any de plor, los Furs disponen que si los herederos del marido no han restituído a la mujer el exovar ni le han pagado el creix, ésta pasará a poseer los bienes del difunto, con la facultad de hacer suyos los frutos ${ }^{4}$. Esto es

1 Ucilizaré indistintamente el término exovar o dote. También creix o aumento de dote.

2 Tarazona, J.: Institucions del Furs y Privilegis del Regne de Valencia, Valencia, 1580, tír. 12, pág. 117: béns dotals se enten que son aquells que la muller porta al marit, axi movens com scents: los quals no poden esser venuts, ni obligats per lo martit, sens la ferma de la muller ab jurament no forçada. $Y$ deu los tenir lo marit, $y$ los fruyts son de aquell: per que soste los carrechs del matrimoni

3 TRULIENCH, J.G.: opus morale sive in decem decalogi, et quinque eccles. Pratecepti absolutissima et resolutoria expositio, ex optimorum novissimorumque doctorum probatissima dactrina deprompa, 2 vols., Valencia, 1960, cap. 18, dub. 12: est autem augmentum dotis, usufructus in bonis maritis correspondentibus dimidiae parti, sest medietati dotis

4 Fori Regni Valentiae, J. Mey, Valencia, 1547-1548: 5.5.6: si morra lo marit: la muller no pusque demanar lexovar dins un any: sils bereus seran aparellats de donar, e de fer a ella tots los obs. Mas romangua 
el llamado derecho de tenuta ${ }^{5}$ el cual, desde que por ley se estableció, siempre se ha observado y en virtud del mismo a las viudas se les concede la tenuta post annum luctus de los bienes que el marido poseía al tiempo de su muerte, en tanto su exovar y creix no le sean restituídos ${ }^{6}$. Los documentos judiciales atestiguan la aplicación estricta de esta disposición foral ${ }^{7}$. Tan sólo hay una excepción, que recoge Bas: cuando el esposo hubiera asignado algunos bienes como garantía del exovar; en este caso, sólo se percibirán los frutos de aquéllos y no de todos

en les coses del marit ensro a un any, e daqui avant pusque demanar lexovar. E sils parents no li volran retre can lany serà complit: tinga ella san longament totes les coses del marit tro sia pagada del exovar, e del creix del exovar, e faga les fruyts seus per aquella part del any que no la bautran pagada; TRULLNCH, J. G.: opus moralie, sive...., lib. 7, cap. 19, dub.14, núm. 12, pág. 400: uxort, si ei ab baeredibus post primum annum luctus dos, et eius augmentum, id est lo creix, ob virginitatem non solvatur, potest retinere omnia bona mariti, et facit fructus suos; LISSA, A.C.: Tyrocinium iurisprudentian forensis sew animadversiones theorico-practical iuxta foros Aragonum, Zaragoza, 1703, lib. 2, tít. 4 de usufructu: similiter in Cathalonia et in regno Valentiae, matrimonio soluto per mariti mortem, si intra annum luctus a die mortis mariti computandum, non fuerit restituta dos et augmentum dosis viduate particularibus constitutionibus stabilitum extat quod vidua elapso anno detineat et possideat omnia mariti bona et fructus suos faciat, quosque fuerit de dose et augmento satisfacta; LEÓN, F.J.: Decisiones sacrae Regiae Audientiae Valentianae, 3 vols., Valencia, Oriola, Valencia, 1620, 1625 y 1646, vol. 2, decis. 122, núm. 7, pág. 29: si intra annum non salvatur dos, et augmentum, babet tenutam in bonis mariti, et facit fructus szos, donec dos ei restituatur.

5 BELDA, $M^{\wedge}$ Angeles: El régimen económico matrimonial de bienes en los Furs de Valencia, Valencia, 1966; GARCfa, Honorio: "La tenuta», Boletín de la Saciedad Castellonense de Cultura, 24,4 (1948), págs. 307-312; Honorio García, "Any de plor», B.S.C.C, 23,2 (1947), págs. 121-127; SÁNCHEZBLaNCO, R Benitez: «Familia y transmisión de la propiedad en el País Valenciano (siglos XVIXVII). Ponderación global y marco jurídicos, Poder, familia y consanguinidad en la España del Antiguo Régimen, Barcelona, 1992; I. Baixauli, «La dona davant la crisi económica del matrimoni: devolucions de dots en la Valéncia del segle XVII", Estudis, 18 (1993), págs. 183-205.

6 Archivo Reino Valencia, Real Axdiencia, procesos segunda parte, exped. 408, 1596: ... ab sentensia real publicada per Lays Bervegal scriva de manament a vint y dos de setembre propassat del present any fonch adjudicada la tenuta e possessio de tots los béns recabents en la berencia de don Alonso de Borja a dona Elionor de Noraña y de Borja relicta del dit don Alonso de Borja fins sia pagada aquella per entregue de la dot per aquella constitubida.

7 A.R.V, Real Audiencia, procesos tercera parte, apéndice, signat. 7.545: lo dit Joan Batiste Alcoser haja molt temps que es mont sens que jamés a la dita supplicant se li baja fet pasgament intra nec extre annum luctus y per conseguent a foro li competeix la tenuta de tots los béns de la berencia del dit Joan Batiste Alcoser; A.R.V, Real Audiencia, procesos de Madrid, exped. 124, fol. 2: tenir la teneo pacifica de aquells fins tant integrament sia pagada de la dita sta dot y creix en la forma y per als effectes per dites dispositions forals dispastes $y$ ordenades sens que puja ni deya esser turbada ni molestada en la retentió, teneo y possessió de tots los dits béns que lo dit don Cataldo Centelles possebia..; Real Audiencia, Procesas de Madrid, 1611, exped. 668, letra $\mathrm{P}$, fol.33: conforme disposicions forals del present regne essent cas de dot $y$ creix restitubidors, la muller 0 viuda té actio pera demanar pagament a tenuta dels bens de son marit quant baura passat un any després de la mort de aquell et non aliter; Gobernación, signat. 3.737, año 1652, proceso entre doña Margarita Tallada y de Ribera, viuda y el curador decretado en la herencia yacente de don Baltasar de Ribera: ... segons dits furs se declare aquella tenutaria en tots los dits béns e que ba fet tots los fruits de aquells a die finiti anni luctus seus propris y de buy en avant ratione tenutae y conseguenment le mane possar en possessio de dits béns..., Sentencia Real Audiencia, caja 80, exped. 9.081, 27 abril 1616, Alrreus, en el pleito seguido entre Esperanza Soler y de Blasco y Jerónima Navasquillo; 
los que pertenecen al marido. Hay que presuponer que las rentas que estos bienes producen son suficientes para garantizar la restitución dotal.

Angeles Belda afirma que la tenuta valenciana es una institución catalana que se trajo a Valencia tras la Reconquista por los repobladores del principa$\mathrm{do}^{9}$; lo contrario afirma Honorio García, quien escribe que dicha figura jurídica fue originaria de Valencia y que se expandió hacia Cataluña, donde los juristas la acogieron y le dieron denominación, puesto que los fueros, aún regulando dicha institución, no le otorgaron ningún nombre específico y ante la necesidad de atribuirle uno, le designaron el que ya había sido admitido por los juristas para designar a esta institución en el Principado ${ }^{10}$.

Se puede observar una evolución dentro de los propios fueros. Así, en un primer momento, únicamente se concede a la mujer la posesión de los bienes del marido premuerto mientras no le sea restituída y pagada la dote y creix, prohibiéndose a los herederos de aquél que toquen o administren alguno de dichos bienes ${ }^{11}$. Posteriormente, los fueros añaden a dicha posesión, la facultad de que la mujer haga suyos los frutos de los bienes del marido en tanto no se le devuelva el exovar, no considerándose dichos frutos como parte del pago ${ }^{12}$.

\section{NATURALEZA}

A esta figura jurídica se la denomina tenuta porque la posesión de los bienes del marido pasa a la mujer por ministerio de la ley. Se trata de una posesión universal, que se extiende a todos los bienes del esposo de los cuales a éste le corresponde la titularidad. Para seguridad y cumplimiento del derecho que la mujer tiene a que se le restituya su dote y se le pague su creix, los fueros le conceden la facultad de que pueda entrar en la posesión de todos los bienes del marido premuerto sin que, entre tanto, nadie pueda despojarla ni privarla de

2 BAS Y GALCERAN, N.: Theatrum iurisprudentiae forensis Valentiae, romanorum iuris, Valencia, 1620, part. 1, cap. 60, núm. 102: ....excepta uxore cui per maritum aliqua bona specialiter fuerint designata pro securitate dotis, ex quibus fructus percipere posset, nam solum in illis bonis provisionem istam babere debet.

9 BELDA SOLER, A.: El régimen matrimonial de biener. pág. 118.

10 GARClA, H.:«La tenuta», B.S.C.C, pág. 307.

1 Fori....., 5.5.8: can lo marit dalcuna fembra serà mort, lo fill o la filla o qualque altre bereu a qui pertenga la beretat per testament o sens testament no pusque alcuna cosa tocar, en aministrar alcuns béns del defunt, en entrar en la passessió daquels béns que foren del marit defunt entrò que la muller sia pagada de l'exovar e la donatió per nupcies $e$ de les altres soses quel marit donà a la muller el temps quel matrimoni fo feit entre ells.

12 Fori..., 5.5.9: Sils bereus del marit satisfaran enfre un any comptat del dia de la mort del marit a la muller del defunct en lexovar, e en l'eppoalici no sien tenguts a ella del temps de la paga a enont de fer sas abs en neguna cosa: mas enans que li bajen satisfeyt ne pagat la dot ne son esposalici: la muller prena les fruits tots dels béns del mari, e aquels siens seus, e la muller no sia tenguda null temps a comptar aquels froyts ne reebre en pagua de sa dot ne de son espoalici.

Hispania, LX/2, núm. 205 (2000) 453-478 
ellos. Esto plantea si dicha posesión consiste en una aprehensión directa o, por el contrario, es posible que se realice sin ella. Cáncer considera que a la mujer, disuelto el matrimonio, no se le transfiere ipso iure el dominio de las cosas dotales, por lo que no puede tomar posesión nisi consentiente baerede mariti ${ }^{13}$ y que, tras la muerte del marido, puede intentar el interdicto de recuperar la posesión contra los ocupantes de los bienes ${ }^{14}$, pues a la viuda, por su tenuta, no sólo se la considera, tiene y juzga como poseedora real y actual, sino que, además, le alcanzan los remedios de adquirir y retener. Fontanella reconoce que la posesión no se transmite $\sin$ animus y corpus, y sin una real y efectiva aprehensión ${ }^{15}$. Según Trobat, no es necesaria ésta ya que, siendo la viuda persona única y cierta, no se plantea entorno a ella ninguna duda por lo que no se le debe retrasar en el goce y disfrute de los bienes dotales y en estos términos lo expresa ${ }^{16}$.

La viuda, por tanto, que quiere ser real y efectivamente tenutaria, puede deducir los interdictos de adquirir y de recobrar si alguien se apodera de todos o parte de los bienes, además de que, puede ejercer la acción de despojo cuando se insta el secuestro de los bienes hereditarios del marido premuerto que se hallan en poder de una tercera persona. Incluso, en caso de ser despojada violentamente de la posesión, puede actuar criminalmente contra quien la ha echado.

Se trata de un derecho cuya existencia no es debida a la viudedad de la mujer, sino que garantiza la restitución de la dote y el pago del creix $x^{17} \mathrm{y}$, por tanto, se le debe incluir dentro de las garantías dotales ya que no es propiamente un derecho de viudedad.

El derecho del any de plor y el de tenuta son dos derechos distintos y de fin diverso, aunque sucesivos en el tiempo, siendo el segundo de contenido más amplio que el del primero, pues el año de luto sólamente comprende alimentos civiles y lutos; cuando concluye, comienza la tenuta, si los herederos del esposo no han restituído el exovar ni han pagado el aumento de dote. Durante su disfrute, la viuda obtiene la posesión y el usufructo de todos los bienes del marido premuerto, cesando el derecho de alimentos. Tienen en común que tanto en uno como en otro, los herederos del esposo deben proveer a la viuda de todo lo

13 CÁNCER, J.: Variarum resolutionem iuris caesarei, pontificii et municipalis Principatus Cathaloniae, Tours, 1617 , part. 1 , cap. 9 , núm. 86

14 CÁNCER, J.: Variarum resolutionem....., part. 1, cap. 9, núms. 32-34

15 FONTANella, J.P.: De pactis nuptialibus, sive de capitulis matrimonialibus, Ginebra, 1684, vol. 2, claus. 7, glos. 3, part. 1, núms. 15-17 y claus. 7, glos. 3, part. 3, núms. 1+17; A. Gómez, Ad leges Tauri commentarium absolutissimum, Madrid, 1780, ley 45, núm. 33: quod omnia iura dicentia, quod solo animo non quacritur possessio, sed nequiritur actus corporeus et animus acquirentis.

16 TROBAT, J.B.: De efectibus immemorialis praescriptionis et consuesudinis, Valencia, 1700, tít. 5 , quaest .9 , cap. 60 de restisutione dotis et augmenti..., núm. 119: tamen in vidua virtute nostri fori, a die finiti anni luctus trasnfertur ipso iture, et absque naturali aprebensione possessio bonorum mariti, et illorum tenuta, neque aliqua declaratione opus est, ut censeatur possessio ista in viduam translata, et ut ipsa posset facere fructus.

17 CANCER, J.: Variarum resolutionem...., part. 1, cap. 9, núm. 179. 
necesario, es lo que se denomina fer sos obs, aunque diferenciándose en que el año de luto implica únicamente la satisfacción de las necesidades de la mujer, mientras que en la tenuta ésta hace suyos todos los frutos de los bienes del marido premuerto, cuyo importe puede ser muy superior a las necesidades reales. Es un paso más en la recuperación de su patrimonio por parte de la mujer viuda.

La tenuta como garantía de restitución dotal no debe confundirse con el derecho de viudedad aragonés. Éste consiste en el derecho de usufructo que corresponde al cónyuge supérstite, mientras permanece viudo, en los bienes inmuebles o sitios del premuerto y lo pierde si contrae nuevas nupcias, lleva una vida deshonesta o comete adulterio, mientras que la tenuta valenciana sólamente se disfruta durante el tiempo en que a la mujer no se le paga la dote y el creix, no perdiéndola por contraer nuevo matrimonio ${ }^{18}$. Así pues, en Aragón se trata de un derecho de viudedad y, en Valencia, la tenuta no es más que una garantía para que el exovar se devuelva y el aumento de dote se pague. En Aragón son bienes privativos los que cada uno de los cónyuges lleva al matrimonio y son comunes todos los muebles e inmuebles adquiridos a título oneroso o mediante el trabajo de cualquiera de los consortes constante el matrimonio, consistiendo la viudedad foral aragonesa en el derecho que cada cónyuge tiene a disfrutar de los bienes privativos del otro y de la parte que a éste le corresponde de los bienes comunes. Este derecho de viudedad se establece para proteger a las mujeres aragonesas cuando se convierten en viudas, especialmente si no tienen hijos, aunque posteriormente este derecho se ampliará y también disfrutarán de él los viudos ${ }^{19}$.

Tiene el derecho tenutario un momento concreto para iniciarse que es al concluir el any de plor, siendo el término en que finaliza variable ya que depende de cuando los herederos del marido premuerto paguen a la mujer su exovar y aumento de dote, pues es entonces cuando la viuda tendrá acción para exigir bien el pago de la dote, bien la tenuta ${ }^{20}$. Si aquéllos, una vez disuelto el matri-

18 LSSA, A.C.: Tyrocinium iurisprudentiae forensis seu ...., lib. 2, tít. 4 de usufructu: nam viduitas durat in boc regno dum viduus sive uxor, sive maritus sit, secunda vota non susceperit... ubi etiam disponitur viduam babentem secum manifestum formicatorem viduitatem amittere, quod secus in viduo...; M. de Molino, Repertorium fororum et observatiarum regni aragonum practicis atque cautelis eisdem fideliter annexis, Zaragoza, 1585 , núm. 21 : viduitate durante retinet vidua bonorem sui mariti, etiam de foro..

19 MoliNo, M.: de Repertorium fororum et observatiarum regni aragonum..., núm. 32: viduitatis ius secundum foristas competit in Aragonia viro, vel uxori beneficio fori in bonis sedentibus coniugis premortui: etiam si allegetur matrimonium non fuisse verum inter coniuges aut legitimam: quia istud iks et alia iura foralia competunt superstiti ex coniugibus in bonis coningis defuncti ex solo matrimotio putasio, quia ad consequendum ista ira sufficti ariculare et probare, quod ambo coniuges vixerunt in figura matrimoni; Trata sobre la viudedad aragonesa $\mathbf{M}^{2}$ Carmen García Herrero, "Viudedad foral y viudas aragonesas a finales de la Edad Median, Hispana, revista española de Histoira, vol.53/1, 183 (1993)

20 A.R. Real Audiencia, procesos de Madrid, 1611, exped. 668, fol. 83: conforme disposicions forals del present regne essent cas de dot $y$ creix restitubidors, la muller o viuda te actio pera demanar pagament o tenuta dels béns de son marit quant baurà passat un any despres de la mort de aquell. 
monio, restituyen inmediatamente, la tenuta no es que cese, es que nunca liega a nacer.

La amplitud de este derecho es tanta que autores como Fontanella denominan a la viuda, que disfruta del derecho de tenuta, videdomina ${ }^{21}$. Se trata de un derecho de garantía que consiste en la posesión de todos los bienes del marido por imperativo legal y que confiere a la mujer el derecho a percibir los frutos, sin que dicha posesión prescriba. La viuda no pierde la tenuta ya que la misma no la tiene por razón del esposo premuerto, sino por establecerlo la ley y por causa onerosa de su dote.

\section{REQUISITOS}

Para que haya tenuta es necesario que haya habido matrimonio y que éste se disuelva por muerte del marido, además de que, efectivamente, la dote se haya pagado en su día a aquél, lo que conlleva a plantear de qué medios de prueba se puede valer la mujer para demostrar que, efectivamente, ha pagado la dote a su esposo premuerto.

Cáncer dice que la confesión que se hace en testamento o en disposición de última voluntad, no prueba el pago de la dote pues el testador puede revocarla $y$, por tanto, no se puede afirmar que ha habido verdadero pago, por lo que tal confesión sólo tiene el valor de un legado o donación ${ }^{22}$. En este mismo sentido se manifiesta Fontanella, el cual afirma que la tenuta no puede disfrutarla la mujer si no tiene, además de la confesión hecha en testamento, otro medio de prueba ${ }^{23}$. La doctrina valenciana considera que la confesión realizada antes o durante el matrimonio es prueba de pago, ya que el marido tiene un plazo de cinco años para alegar la excepción non numeratae dotis, cuando dicha confesión se realiza antes del matrimonio y en las mismas cartas dotales. En cambio, si se efectúa constante el matrimonio y fuera de la escritura de dote, únicamente dispondrá de un plazo de treinta días para poder interponer dicha excepción ${ }^{24}$. Si transcurren cinco años desde la fecha en que se celebraton las nupcias y el marido no ha reclamado la dote prometida, se considera que la misma se ha pagado.

En la práctica, generalmente, se prueba que la mujer ha efectuado el pago del exovar mediante las cartas dotales, por considerar que las palabras que en

\footnotetext{
21 FONTANELLA, J.P.: De pactis nuptialibus....., vol.2, claus .6, glos.1, part. 2, núm. 33.

22 CANCER, J.: Variarum resolutionem....., part. 1, cap. 9, núm. 54: quando talis confersio fit in ultima voluntate, est exploratum, veram numerationem dotis non probare, sed tantum donationem inducere..... noctum est posse testatorem talem confessionem quoties vohverit revocare quad non esset si veram numeratione probare.

${ }^{23}$ FONTANella, J.P.: De pactis nuptialibus....., vol. 2, claus. 7, glos. 1, part. 2, núm. 73:quod mulier non babet aliam probationem dotis, quam desumitur ex confessione facta in testamento, non gaudet beneficio....

24 BAS Y GAlCERán, N.: Theatrum ierisprudentiae....., part. 1, cap. 8..., núm. 4.
} 
ellas se recogen, expresan de un modo claro un traslado de la posesión de los bienes dotales, junto con la ápoca continuada al pie de las mismas; pero, en ocasiones, los herederos del marido premuerto se niegan a que se le reconozca a la viuda este derecho, afirmando que las cartas no son documento suficiente para acreditar que la posesión de los bienes se ha transferido realmente, lo que viene reforzado si no se ha firmado carta de pago ni al pie de la escritura dotal ni posteriormente y, además, se ejerció acción non numerata pecunia dentro del plazo establecido por los propios fueros para exigir la dote no pagada y, así se ve reflejado cuando quien debe restituir, alega a su favor que debe ser quien reclama su derecho, el que debe probar el pago ${ }^{25}$.

El problema de la confesión de recibida la dote efectuada por el marido, constante el matrimonio, es si con la misma se está tratando de encubrir una donación entre cónyuges, la cual está prohibida. Para descartar la sospecha, es fundamental que haya precedido promesa, ya que en tal caso se presume que la confesión se ha realizado con ánimo de un futuro pago, pero si nunca hubo tal promesa, ni se realizaron cartas dotales, entonces se considera que con ello se está encubriendo una donación.

Muerto don Cristóbal Despuig, su viuda procede a pedir el que se le reconozca su derecho de tenuta, tal y como establece la legislación foral ${ }^{26}$. Argumenta en su favor que la dote fue constituida y pagada, tal y como se refleja en primer lugar, en las propias cartas dotales firmadas entre don Francisco Bou y don Cristóbal Despuig y, en segundo lugar, en la propia carta de pago realizada ante notario el día 7 enero 1641 y firmada por este último, en la que consta que restituý́ parte de la dote, faltando el resto de la misma y el creix. La sentencia dictada reconoce dicho derecho de tenuta por cuanto que los documentos presentados son prueba suficiente para demostrar que efectivamente el exovar fue constituido y entregado al marido premuerto y, que habiendo restituido parte del mismo, falta el resto.

Además de los requisitos de que haya habido matrimonio y que la dote se haya entregado, el derecho catalán agrega un requisito más, que las viudas hagan inventario de los bienes dentro de los dos meses a contar desde que tienen conocimento de la muerte del esposo, pues el no iniciar y concluir su realización dentro del término señalado, conlleva la pérdida de este beneficio, es

25 A.R.V, Real Audiencia, procesos de Madrid, exped. 124, pleito entre Dña. Brunisa de Perellós contra Don Cristofol Centelles: nos pot dir que y hague tácita confessió $y$ en cas que la yagkera (quod semper negative) puix noy bagte ápoca fermada, aquell opposar com opposa la exceptio non numeratae dotis infra dictum quinqueniwm, la qual exceptio ha obrat y otra que la part altra ba de provar la numeratio vere realiter et plene et non per vanas praesumptiones curia liter parlant

26 A.R.V, Gobernación, signat. 3.736, año 1652, proceso entre doña Marina Bou y de Despuig con Despuig y Tortes: que ab los actes $y$ documents presentats en proces sufficientement queda justificada la intenció de la dita dona Merina Bou... pronuncia sentencia y declara la dita instancia quedar justificada et consequenter competirle a la dita dona Merina Bou la dita tenuta en tots los béns del dit don Chistofol Despuig, son marit.....

Hipennia, LX/2, núm. 205 (2000) 453-478 
decir, no puede hacer suyos los bienes del esposo premuerto, aunque en las capitulaciones matrimoniales se hubiera dispuesto lo contrario ${ }^{27}$. En cambio, en el Reino de Valencia, los fueros no exigen el que la viuda tenga que realizar dicho inventario y así lo corrobora la propia doctrina. León dice que en Cataluña se observa una costumbre contraria a la que se realiza en Valencia que consiste en que las viudas están obligadas a efectuar inventario ${ }^{28}$.

Para que la mujer pase a poseer los bienes de su marido muerto, debe constar fehacientemente que pagó la dote a éste, ya que si no puede demostrarlo no podrá despojar a quien esté poseyendo los bienes.

\section{BENEFICIARIOS DE LA TENUTA}

Como se ha dicho, la tenuta corresponde a la mujer cuando disuelto el matrimonio por muerte del marido, no se le restituye la dote ni se le paga el creix. Esto lleva a plantear si dicho derecho, también, corresponde a la mujer que se hubiese separado de su marido cuando éste muere. La doctrina valenciana en este punto guarda silencio, pero no así catalana que considera que compete no sólo a la viuda sino, incluso, a la divorciada cuando la separación no haya sido por motivo que produzca la pérdida de la dote $e^{29}$, al igual que también le compete a la mujer que contrajo matrimonio de buena fe existiendo un impedimiento dirimente ${ }^{30}$.

En la práctica, la mujer separada a la que no se le pagan las pensiones correspondientes del censo constituído en pago del creix, no puede disfrutar del derecho de tenuta con del privilegio de hacer suyos los frutos, pues no es viuda, ya que su matrimonio no se ha disuelto por muerte, sino por separación. En este caso, tiene que acudir a la Real Audiencia para solicitar que se obligue a su marido a que preste caución fiduciaria, pues de lo contratio se verá privada del creix,

${ }^{27}$ CÁNCER, J.: Variarum resolutionem...., vol. 1, parc. 2, cap. 9, núm. 26: mortuo viro si faciant inventarium de bonis viri intra dus menses post mortem mariti, incipiendo illud intra unum mensen, et perficiendo illud intra alium mensem..... quad si vudva intra dictum tempus non fecerit inventarium, privatur victu et vestitu sibi dando dicto anno luctus per baeredes viri et insuper commodo faciendi suos fructus bonorum viri post annum luctur; J. Fontanella, De pactis nupsialibus...., vol. 2, claus. 7, glos. 3, part. 2, núm. 4, pág. 482: in qua constitutio non vult currere tempus, quod praefigit ad conficiendum inventaritum, nisi a die scientia mortis mariti, et sic non currit tempess ignoranti.

${ }_{28}$ L.Eón, F.J.: Decisioner sacrae ....., vol. 2, decis. 123, núm. 18: in Cathalonia servatur contrarium, viduam teneri facere inventarium.

29 FONTANELLA, J.P.: De pactis nuptialibus...., vol. 2, claus. 7, glos. 3, part. I, núm. 29:ultimo ast utile videre, an mulieri quae licet a principio cum marito cobabitaret, repetitur tamen ab eo tempori mortis separata, competat benteficium buius constitutionis; claus. 5, glos. 8, part. 10, núm. 38; J. Cáncer, Variarum resolutionem....., part. 3, cap. 11, núm. 112: et sic ubi uxor iudicio ecclesiae separata esset a viro, quoad thorum, ob viri saevitias gaudebit beneficio constitutionis, bac nostra..

30 FONTANELlA, J.P.: De pactis nuptialibus..., vol. 2, claus. 7, glos. 3, parc. 1, núm. 21: mulier enim putativae etiam competit beneficium istud. 
especialmente cuando todas las ejecuciones realizadas sobre los bienes de aquél son imposibles por carecer de bienes.

Se plantea la cuestión de si una vez muerta la mujer, el derecho de tenuta con la facultad de hacer suyos los frutos se transmite a los hijos herederos de la madre. Algunos autores entienden que sí disfrutan éstos de dicho beneficio por razón de la dote no pagada, considerándose que este derecho se transmite a los hijos en virtud del derecho de filiación. Además, estiman que si la viuda puede ceder la acción para reclamar la dote a sus herederos, también puede transferir el privilegio de tenuta con la facultad de hacer suyos los frutos al cesionario, aunque no se transmitirá este derecho cuando los herederos sean nietos o no sean parientes de la mujer, en cuyo caso sólo tienen la retención de los bienes hasta que la dote sea pagada ${ }^{31}$. A los herederos, nietos de la viuda o que no son parientes de ésta, sólo les corresponderá la retención de los bienes hasta que la dote sea totalmente pagada, pero no la facultad de hacer suyos los frutos que dichos bienes produzcan.

Otros autores, como Bas, consideran que la tenuta con dicha facultad no se transmite a los hijos herederos de la viuda por las razones siguientes: en primer lugar, porque este privilegio se concede de modo personal a la viuda y muerta ésta, expira aquél. Y en este sentido se expresan los fueros cuando dicen que la mujer posea durante todo el tiempo los bienes del marido hasta que se le restituya la dote y se le pague el creix, con la facultad de hacer suyos los frutos producidos por dichos bienes ${ }^{32}$. En segundo lugar, porque los fueros no dicen nada acerca de que dicho beneficio se extienda a los hijos herederos de la mujer viuda. En tercer y último lugar, porque existe un interés público en que la mujer no esté indotada, de ahí que los Furs recojan la figura de la tenuta con la facultad de hacer los frutos suyos, pero este interés sólamente reside en la mujer y no en sus hijos, por eso a éstos no se les concede la tenuta. Así, en sentencia dictada el día 22 de diciembre de 1628 contra Marcos Antonio Alzamora, se dice que el derecho de tenuta que la mujer tiene sobre los bienes del marido no se extiende a sus herederos ${ }^{33}$.

31 CÁNCER, J.: Variarum resolutionem...., part. 1, cap. 9, núm. 59: si vidua quae babet tenutam in bonis viri pro sua dote et sponsalitio decedat, an illud ius retinendi dicta bona pro dicta dote et sponsalitio, et faciendi fructus ditorum bonorum suos, transmittat ad suos hatredes? intellege de filis eitusdem marisi, secus de filits alierius mariti; FONTANELLA, J.P.: De pactis nuptialibus..., vol. 1, claus. 7, glos. 3, parr. 7, núm. 1: quod donec satisfactum sit mulieri in sua dose est sponsalitio durat beneficium constitutionis, tam reppectu tenutat, quam etiam quoad acquisitionem fructurm. Quaero an id etiam inteilligatur post stuan ipsius montem, id est, an batredes suctedant in dita tenuta, et etiam in benteficio faciendi fructur stor.

32 Fori..., 5.5.6: esils parents no li volran netre can lany serà complit: tinga ella tan longament totes les coses del marit tro sia pagada del exovar, e del creix del exovar, e faça las fruyts seks per aquella part del any que no la hauran pagada.

33 BAS Y GALCERAN, N.: Theatrum iurijprudentiae...., part. 1, cap. 60..., núm. 113: et atsento qudo licet per foros Regni concessum sit mulieribus propter suas dotes ius tenutae cum facultate faciendi fructus suos baereditatis mariti, boc tamen ius eum exarbitans, correctorium et periculosum ob suspitionem faenoris sit, nec etiam ad filios baeredes extendi de iure debet. 
A los hijos herederos sólo se les da la posesión de los bienes, pero sin la facultad de hacer suyos los frutos, es lo que vulgarmente se denomina teneo y ello porque dichos frutos deben imputarse al crédito debido, esto es, al exovar no pagado ${ }^{34}$; de modo que, si perciben dichos frutos, éstos se imputarán a cuenta del pago de la dote. Cuando los hijos y herederos quieren el teneo o la posesión, deben pedirla en forma ${ }^{35}$.

Por tanto, la doctrina entiende que dicho derecho de tenuta no se transmite a los herederos aunque sean parientes de sangre de aquélla, por lo que no pueden hacer suyos los frutos de los bienes del marido premuerto y, en caso de hacerlo, se deben computar a cuenta del crédito debido ${ }^{36}$.

En los pleitos que se siguen en la Real Audiencia entre el Conde de Carlet y los administradores de la herencia de doña Mariana de Bracamonte, Condesa viuda de la Alcudia y Gestalgar ${ }^{37}$ se afirma por parte de dichos administradores que, aunque la viuda disfrute de la tenuta, este derecho no se transmite ni pasa a sus herederos, a quienes sólo les corresponde el teneo, hasta que con los frutos de los bienes retenidos se satisfaga el exovar. Se plantea la cuestión de si todos los frutos se han de computar para el pago de la dote y el aumento o, por el

34 N. Bas y Galcerán, Theatrum iurisprudentiate.., pars. 1, cap. 60..., núm. 113: solum filiis baeredibus detur buiwsmadi insistentia, et possessio iure pignoris, vulgo Teneo absque facultate faciendi fructus suos... ratione bypotecae dotalis tenutam istam bonorum baereditatis mariti, fructus quos perceperint, debent imputare in sortem crediti.

35 BAS Y GALCERAN, N.: Theatrum iurisprudentiae.., part.1, cap. 60, pág. 589:. .. fill y bereu de la quondam,..., sa mare, suplicant com millor pot, diu, que al temps, y quant contracta matrimoni la dita...., sa mare, ab...., li constituhy en dos la cantitat de ..... les quals confessa aver bagut y rebut, segorn consta ab la ápora continuada al peu de dites cartes matrimonials, de que fa presentacio, si, et in quantum; $y$ sent aixi que molts anyus ba que mori la dita...., sa mare, $y$ lo dit..., pare del suplicant y marit de la dita..., avia mort molts anys abans, no se ba cuidad de restitubir lo sobredit dot; e com segons disposicions de justicia, per no averse pagat dit dot intra annum luctus, li compeseixca al supplicant la tenuta, eo teneo en tots los bens que sempore moris, lo dit..., son pare possebia. Pertant et alias, omni meliori modo, et utendo remedio quo magis expediat, supplica es mane declarar competirli al suplicant, lo teneo de dits bens, manantli donar la possessió de aquells, iure pignoris, et bypotbecat pera que els detinga, y passebeixca quousque sit soluta ab integro de dit dot e interessos discorreguts de aquell...

36 TARRAZA, G.: Diversorum Instrumentorum contractum et ultimanum voluntatum, iuxta magis communeva Compendium sive epitbome Theoricae artis notariae in quo de illa, et de tribus ipsius printipalibus partibus, scilicet, de contractibus, ultimus voluntaribus et iudiciis brevissime agitur, Valencia, 1636, Cap. 45 de dotibus, nuptiis et augmento: at dictum ius tenutae non transit ad illius baeredes, etian si sint de sanguine, et illi no faciunt fructus suos, prout ipsa vidua faciebat, sed debent illos in suzm creditum computarem. Et ita fuit declaratum cum supraedicta sententia publicata per dictum Alreus, die 5 julii 1.589.

37 B.Universitaria, Varios, signat. 96, núm. 13, informe jurídico por los administradores de la administración y universal herencia de doña Mariana de Bracamonte, Davila, Pacheco y Portugal, Condesa viuda de la Alcudia y Gestalgar, Marquesa de Trosifal y Montalvan, en los pleitos que penden en la Real Audiencia con don Joaquín de Castelví, Escrivá de Ixár, Conde de Carlet sobre el recurso introducido por parte de dicho Conde de Carlet, pretendiendo que se declaren nulos los autos de tenuta, que viviendo ganó y obtuvo dicha condesa, y pretensión de que se revoquen los autos de teneo, que después de la muerte de aquella lograron sus administradores, y pongan en sequestro los bienes y rentas de los mayorazgos que poseen. 
contrario, se deben también satisfacer los intereses correspondientes al capital del exovar y creix todavía pendiente de pago. Se afirma que, dado que las capitulaciones matrimoniales se realizaron estando aun vigentes los Fueros, debe observarse la práctica seguida por aquél entonces que era favorable a la satisfacción de dichos intereses, apoyándose la argumentación en dos sentencias pronunciadas el 15 septiembre 1671 y el 8 marzo 1675 a favor del marqués de Benavites, cuyo heredero el Marqués de Bélgida posee por teneo la Baronía de Ribarroja y percibe los frutos de los intereses correspondientes al capital de la dote.

Concluyendo, cuando muere la viuda que disfruta del beneficio tenuta, aunque deje hijos herederos, a éstos no se les transmite aquél, sino sólo la posesión de los bienes de dicha herencia pero sin la facultad de hacer suyos los frutos, de modo que si los perciben, deben hacerlo en concepto de pago de dote. La razón de esta posesión es la hipoteca que se tiene y que obliga a dichos bienes hereditarios a responder de la restitución del exovar.

De este derecho no se puede ni expresa ni tácitamente privar a las viudas siempre que se den los requisitos necesarios para su existencia. Si éstas contraen segundas nupcias dentro del año de luto, no pierden la tenuta, pues este derecho no se considera un beneficio otorgado por el marido sino que el mismo lo establece la ley. Son los propios fueros quienes reconocen la tenuta a la mujer por razón del exovar y del creix no restituído y pagado, por lo que al no proceder del esposo, la viuda aunque cometa fornicación o adulterio, no pierde dicho benefi$\mathrm{Cio}^{38}$.

\section{BIENES SOBRE LOS QUE RECAE}

En este apartado se trata de ver si la tenuta se extiende a todos los bienes del marido o, por el contratio, algunos de ellos escapan a dicho derecho.

Autores, como Cáncer, consideran que, en los bienes que el marido ha donado en vida, aunque los esté poseyendo, no pueden ser objeto de tenuta. A esta excepción, se establece un límite que tiene lugar cuando se realizan grandes donaciones cometiendo fraude con ello, como son las donaciones inter vivos hechas a los hijos nacidos del segundo matrimonio ${ }^{39}$. Tampoco deben comprenderse dentro de este derecho los bienes de los cuales el marido únicamente tiene el usufnucto. Por ello, la doctrina considera que no cabe la tenuta en los

38 BAS Y GALCERÁN, N.: Theatrum iurisprudentiae..., part. 1, cap. 60...., núm. 103: ..illud habeat vixda virtute fori, et non beneficio mariti, non amitet iura tenute per fornicationem, aut in bonestam vitam.

39 CANCER, J.: Variarum resolutionem.... part. 1, cap. 9, núm. 42: vidua non censetur passidere bona quas maritus in vita donowit et qumstotior se nomine donatarii possidere. Non procedere dispositionem statuti continuantis possessionem, extante in medio donatione: quad ego in facti contingentia limitavi, in quadam magna donatione inter vivos, per patrem facta cum iuramento filio secundi matrimoni: dixi siquidem dictam donationem censeri in fraudem ..; PONTANELA, J.P.: De pactis nuptialibus...., claus. 7, glos. 3, part. 3, núm. 34. 
bienes que el padre ha donado a los hijos nacidos del primer matrimonio y de los cuales se reservó el usufructo ${ }^{40}$.

Sobre la cuestión de si la mujer tiene derecho de tenuta sobre la cantidad de dinero que el marido se reserva tras haber donado todos sus bienes, Fontanella considera que a aquélla le corresponde este derecho en los bienes cuyo valor sea equivalente a dicha cantidad, para que así pueda hacer suyos los frutos de la misma en tanto la dote no le sea pagada ${ }^{41}$.

Respecto a los bienes vinculados, los autores se encuentran divididos pues, frente a unos que consideran que dicho derecho no puede recaer sobre los mismos ya que no son propiamente del marido, otros autotes estiman que aquéllos pasan tras la muerte de éste a la viuda ipso iure por razón de la dote no restituída, aunque dichos bienes fuesen de posesión transitoria. Fontanella expone argumentos de una u otra posición, señalando que la tenuta tiene su razón de ser en que la mujer no pierda su dote y no para que obtenga un lucro, señalando que la misma no puede hacer suyos los frutos de unos bienes y de otros no, además de que no debe ser perturbada en su posesión por el hecho de que los bienes sean vinculados.

En el Reino de Valencia, la tenuta con la facultad de hacer suyos los frutos se da no sólo sobre los bienes libres sino, incluso, sobre los vinculados por ascendiente en defecto de libres, aunque algún autor considera que no se debe dar sobre bienes sujetos a fideicomiso ${ }^{42}$.

$Y$, por tanto, a efectos de este derecho, los bienes sujetos a vínculo se equiparan a los bienes libres cuando éstos son insuficientes para la restitución del exovar y el pago del $c r e i x^{43}$, aunque esto no tiene lugar cuando la mujer no po-

40 Fontanella, J.P.: De pactis nuptialibus....., vol. 2, claus. 7, glos. 3, part. 3, núm. 34: et in terminus terminantibus quad in bonis donatis ante mortem, in quibus usumfructum sibi reservaverit maritus, non babet mulier tenutam.

41 FONTANELlA, J.P.: De pactis nuptialibus....., vol. 2, claus. 7, glos. 3, part. 3, núm. 35: quod quia donator reservaverat sibi viginti mille libras ad testandum, pro eis competebat muliere tenuta in parte bonorum aequivalenti praedictae quantitat, ad quam partem tradendam mulieri, ut eius faceret fruttus suos dum dos sibi non solveretur.

42 BAS Y GALCERÁN. N.: Theatrum iurisprudentiae. part. 1. cap. 60, núm. 106: datur tenuta foralis cum facultate faciendi fructus suos, non solum in bonis liberis mariti, sed etiam in bonis vinctlatis ascendentikm quate maritus possidebat restitutioni subiecta, nam licet aliqui voluerint, non esse dandam temutam in bonis fideicommisso subiectis; LEÓN, F.J.: Decisiones sacrae...., vol.2, decis. 122, núm. 6: bonis liberis mariti deficientibus, quae sufficiant ad integram dotis, et augmenti, sive creix solutionem, uxorem babere tenutam in bonis fideicommisso subiectis per ascendentes mariti

43 LEón, F.J.: Decisiones sacrae...., vol. 2, decis. 123, núm. 2: quia bona fideicommisso subiecta que maritus gravatus tempone mortis possidebat, aequiparantur bonis liberis ad effectum tenutae, ubi bona libera non sufficient ad dotis et axgmenti solutionem..; TROBAT, J.B.: de efectibus immemorialis...., tít. 5, quaest.9, cap. 60 de restitutione dtis et augmenti..., núm. 121: tenuta foralis, cuitus virtute uxor post annum luctus si non fuit ei soluta dos, et augmentum, valgo dictum creix, facit fructus suos bonorum quod maritus tempore mortis possidebat, etiam si esset fideicommisso subiecto, in defectum liberorum. 
see los bienes fidecomisos ni realiza la petición de la tenuta contra el fidecomisario que los posee $e^{44}$.

El derecho de viudedad aragonés recae en bienes tanto libres como vinculados, diferenciándose de la tenuta valenciana, la cual recae sobre todos los bienes que el marido posee al tiempo de su muerte, excepto los vinculados que sólamente quedaran sujetos en caso de que los bienes libres del esposo premuerto no sean suficientes para poder pagar íntegramente la dote y el creix ${ }^{45}$. Cuando los herederos no pueden pagar por no haber bienes libres en la herencia, la viuda tiene su derecho sobre los bienes vinculados por ascendiente de su marido, de ahí que se diga que la tenuta sobre dichos bienes tiene un carácter subsidiario: "bonis liberis mariti deficientibus, quae sufficiant ad integram dotis, et augmenti, sive creix solutionem, uxorem habere tenutam in bonis fideicommisso subiectis per ascendente mariti, et quase dictus eius vir tempore mortis possidebats ${ }^{46}$.

En el supuesto de que los vinculados por ascendiente paterno del esposo no sean suficientes para la restitución, la tenuta recaerá sobre los bienes sujetos por ascendiente materno, los cuales sólo estarán obligados no existiendo por línea paterna. No se tiene derecho sobre el fideicomiso constituído por un extraño o pariente transversal porque dichos bienes no están obligados a la restitución del exovar y al pago del creix, siendo ésta la causa por la que nace este derecho ${ }^{47}$, esto es, para dar seguridad a las dotes y castigar a quienes están obligados a restituir. Son los propios fueros quienes disponen que, en los bienes vinculados por transversal, aunque el marido los posea al tiempo de su muerte, no quepa la tenuta ${ }^{48}$.

También se da la misma sobre bienes vinculados cuando habiendo bienes libres, éstos no son suficientes para poder pagar plenamente. Pero si los libres que hay en la herencia son bastantes para el pago, no se podrá dar la tenuta sobre los sujetos a fideicomiso.

\footnotetext{
44 LEÓN, F.J.: Decisiones sacrae...., vol. 2, decis .123, núm. 22: non debet extendi ad casum in quo vidua non fuit in possessione bonorum fideicommisso recadentium, ner obtulit petitionem tenuta contra fideicommissatiam possidentem.

4s LISSA, A.C.: Tyrocinium iurisprudentiace...., lib. 2, tít. 4 de usufructu: ius nostrum viduitatis consistit tantum in bonis sedentibus sive baec libera sint sive fideicommisso subiecta....ausem tenutae ius datur in omnibus bonis maviti, quae possidebat tempore mortis, non autem in bonis fideicommisso supasitis, in quibus locum tenuta non bates, nisi in cask quo viri libera non sufficiant ad solvendam integram dotem eiwsque augmentum.

46 LEÓN, F.J.: Decisiones sactae..., vol.2, decis.122, núm. 6.

47 BAS Y GALCERÁN, N.: Theatrum iurisprudentiae ..., parc. 1. cap. 60 núm. 106: quod in fideicommissis lineae matemae, ...... non babebit locum tenunta quando fideicommissi bona linee paternat, sed solum in subsidium, et casu in quo ex fideicommissi paterni bonis, nequit dos, et augmentum ab integro solvi..

4s Fori..., 6.6.7: E sil testador establirà o farà bereu alci que no sia son fill: mas serà san frare, o sont oncle, o son cosi, o qualque bom estrany, e manarà a aquell beres que, si morrà ab infants o sens infants, que restituesca aquella beretat, o aquella cosa que li baurà a alcú aytal substitució o vincle dur per tots temps. Agó, emperò, saluu e entès que aquel qui sera bereu establit pusque retenir a si la quinta part dels béns quel testador li baurá manat de restituir a alcú.
} 
En el informe jurídico realizado por los administradores de la administración y herencia de doña Mariana de Bracamonte en los pleitos que se siguen en la Real Audiencia con don Joaquín Castelví, Conde de Carlet ${ }^{49}$ se alega que a doña Mariana le corresponde la tenuta ya que, transcurrido el año de luto, la viuda adquiere ipso iure tal derecho sobre todos los bienes poseidos por el marido premuerto con la facultad de hacer suyos los frutos y sin obligación de imputarlos a la fuente principal hasta estar enteramente pagada de su dote y aumento. Y esto procede tanto en los bienes libres como en los vinculados, siendo este criterio admitido por los tribunales, salvo en el caso de que los primeros sean suficientes para el entero pago del exovar y del creix, en cuyo caso no resultan obligados los segundos. Pero sí lo están en el caso de que los bienes libres sean insuficientes y ello aunque los fundadores del vínculo hubiesen prohibido expresamente la enajenación de los mismos por esta causa.

Así pues, estos bienes están obligados subsidiariamente tanto a la constitución como a la restitución dotal y, por consiguiente, también lo están por razón de tenuta. Y esto no sólo porque lo establece la legislación del reino, sino también porque no se priva de la propiedad al sucesor; sin olvidar que el derecho tenutario se establece por razón de interés público para el cual es importante la conservación y el prestigio de las familias, además de favorecer la posibilidad de encontrar mujeres de igual posición con las que poder contraer matrimonio aquellas personas de clase social alta. Es este uno de los motivos por los cuales se permite el gravamen en los bienes vinculados.

Según Bas, la mujer que permite la enajenación de los bienes libres del marido, de los cuales se puede realizar el pago, no tiene derecho de tenuta sobre los sujetos a fideicomiso, por cuanto que ella ha hecho posible que su dote no pueda serle satisfecha $a^{50}$. Pero, aunque el marido haya dilapidado todos sus bienes libres y la mujer lo sepa, no puede ésta perder su exovar. Si la esposa tiene acción, crédito e hipoteca en los bienes vinculados es porque dichos bienes están tenidos y obligados a la restitución y, por consiguiente, cabe en ellos la tenuta. Además de que, sólo se atiende al tiempo en que se ha de devolver el exovar y si llegado el momento de hacerlo únicamente hay bienes vinculados, la dote se pagará con éstos, tal y como se establece en los Furs ${ }^{51}$.

49 UNIVerstrarla, B.: Varios, signat. 96, núm. 13.

so BAS Y GALCERÁN, N.: Theatrum iurisprudentiae...., part. 1. cap. 60... núm. 106: si la vidua permisserit alienare bona libera mariti ex quibus solvi poterat dos, es augmentum, aut firmavit in alienationibus.....non dabitur ei tenuta in bonis vinculatis, et fideicommissi

s1 Fori..., 6.6.11: emperì, si la legitima d'aquel qui serd̀ establit bereu bastarà a l'exovar que ell baurà reebut e a la donatio per núpcies que ell baurà feyta e al preu de les coses que ell bautà venudes, jasia gुo que aquela donatió per núpcies sia major que no és establit en la costum de Valencia, la muller pusque tota la dona3ib per núpcies que serà feita a ella en temps de núpcies conseguir plenerament, e les lexes que a ella seran feites el testament de son marit. Dementre, emperò, que a toter aqueles coses que damunt son dites la legitima danunt dita abast. Si, emperò, la legitima o neguns altres béns d'aquel qui serà ertablit bereu no apparran en seran, la 
En la práctica este último criterio es el seguido, así en sentencia de 8 de agosto de 1615 se reconoció derecho de tenuta a la viuda y se declaró que debía cobrar de los bienes vinculados, pese a que aquélla conocía que su marido había enajenado los bienes que su padre le había dado para asegurar la dote y el creix e, incluso, la mujer se obligó en el censo que constituyó su marido ${ }^{52}$.

Los conflictos surgen cuando el marido ha enajenado todos sus bienes libres y los mismos se hallan en poder de un tercero, pretendiendo la mujer su derecho de tenuta en los bienes vinculados de su esposo. En estos casos, los herederos de éste alegan que no puede ir la mujer contra dichos bienes, sino que antes debe reclamar contra los terceros poseedores, especialmente cuando aquélla ha consentido tácitamente que el marido dilapidase sus bienes. Este criterio va contra la opinión de autores, como Cáncer, que entienden que es elección de la mujer el ir contra los bienes vinculados o contra los terceros poseedores ${ }^{53}$. En los fueros se especifica que por la dote quedan obligados los bienes vinculados ${ }^{34}$.

Por lo que resulta que la viuda no está obligada a ir contra terceros poseedores pues antes se le permite reclamar contra los bienes vinculados. Se justifica esta acción contra dichos bienes en el propio privilegio dotal, al igual que también para favorecer la celebración de matrimonios y evitar fraudes ya que los maridos pueden malgastar todos sus bienes y se entiende que es más justo que se favorezca a la esposa que al fidecomisario.

En el pleito que tiene entablado doña Ana de Perellós, viuda, condesa de Buñol, con don Gaston Mercader, por restitución de dote, creix y tenuta, se alega que los fuetos disponen que los bienes vinculados por ascendiente se pueden enajenar para la constitución o restitución de la dote, no distinguiendo si la mujer vió o no que el marido vendía sus bienes, por lo que el exovar y el creix se han de pagar de los vinculados, aunque el marido haya disipado los bienes libres y trate de defraudar al fideicomisario, incluso, sabiéndolo la esposa. Sólo se ha de atender al momento de la restitución ya que la esposa no puede perder su dote ni las garantías que tiene sobre los bienes vinculados. Si al arbitrio de aquélla se deja la decisión de pedir o no el exovar cuando vir vergit ad inopiam, no puede ser castigada a perder aquél junto con el creix por no haber reclamado

muller recobre dels béns que seran vinclats a aguel qui serà substituit l'exovar quel marit baurà reebut d'ella, $\varepsilon$ La donatió per núpcies que serà feita a ella per aquela part per la qual donà 2 comptà l'exovar al marit

s2 LEÓN, F.J.: Decisiones sacrae...., vol. 2, decis. 122, núm. I

s3 CÁNCER, J.: Variarum resolutionem...., part. 2, cap. 9, núm. 171 : circa praddicta obiter advertere non abs re erit, quod si gravatus constante matrimonio alienaserit legitimam, et trebellianicam, et bona alienata appareant: posse successorem fideicommissi, quatenus coactus fuit solvere uxori gravati pro sua dote et sponsalitio, de bonis suis eri pere ex dica legitima, et trebellianica e manibus emptorum... censeat tali casu, id onus mulieri incumbere, ita ut non possit alias consequi bona fideicommissi, nisi prius adversus dictos tertios passessores egerit. Dicens esse in electione mulieris, an velit consequi dotem ex tertiis possessoribus, an ex reliquis bonis fideicommissi..

s4 Fori....., 6.6.7: encara que les coses que deten ésser restituides o que seran vinclades a alck, no poden ésser alienades ne obligades, si donos no seran donades en exovar o en donatió per nipcies segons la qualitat e la bonestat de les persones que faran lo matrimoni..

Hispania, LX/2, núm. 205 (2000) 453-478 
la restitución durante el matrimonio, siendo que la propia ley deja tal cuestión a su libre criterio. Añade que la esposa no está obligada a ir contra terceros poseedores, sino que puede reclamar contra los bienes vinculados, ya que se trata de privilegiar las dotes para favorecer las nupciass.

La viuda, cuando tiene su derecho sobre bienes vinculados, no hace suyos los frutos desde el día en que termina el any de plor, ni desde el día en que se dicta sentencia reconociéndosele el derecho de tenuta, sino desde el día en que lo reclama judicialmente y ello es porque antes no puede considerarse que, por parte del fideicomisario, ha habido mala fe o que ha incurrido en mora, pues siempre se presume y se cree que los bienes libres son suficientes para poder restituir ${ }^{56}$.

Por las mismas causas alegadas en relación a los bienes vinculados, debe darse la tenuta sobre bienes que se encuentran fuera del reino, pese a que algunos autores entienden que ello no es posible porque no se pueden aplicar nuestros fueros en otros territorios y porque para cualquier tipo de contrato, venta, etc... deben utilizarse las normas del lugar donde se hallan los bienes"7.

La viuda tiene derecho de tenuta tanto en los bienes que se encuentran dentro del reino como en los que están fuera del mismo, ya que se debe atender a las leyes donde el esposo tiene su domicilio y no a las lugar donde los bienes se hallan o donde se celebra el contrato, añadiendose para reforzar dicho criterio que el derecho de viudedad en Aragón se da tanto sobre los bienes que el marido tiene dentro como fuera de éste ${ }^{58}$.

Cuando la viuda, que contrae nuevo matrimonio, aporta como dote al mismo la que ya llevó al anterior, los réditos de los bienes constituídos en tenuta son para el esposo, pues están ocupando el lugar de los frutos dotales. Pero si la mujer no ha especificado que los bienes aportados son los mismos que dió en su primer matrimonio, el nuevo marido no adquirirá dichos réditos, pues éstos tienen la consideración de bienes parafernales.

A aquélla sólamente se le debe dar la tenuta sobre los bienes que, terminado el any de plor, se encuentran en la herencia del marido o en los bienes que, du-

5s B. Universitaria, Varios 46-12, alegación jurídica por la egregia Doña Ana de Perellós, viuda condesa de Buñol, con don Gaston Mercader, del hábito de Montesa, en las causas de restitución de dote, creix y tenuta que pretendió dicha condesa en el estado de Buñol y dernás bienes que al tiempo de la muerte poseía el conde Don Laudomio Mercader, su marido.

56 LEÓN, F.J.: Decisiones sasrae...., vol. 2, decis. 123, núm. 15: fructus bonorum in fideicommisso recadentium a die petitionis tenutae, eet sic non simpliciter ad iudicavit viduale fructus a die finiti anni luctus, ut ipsa pratendebat, nec a die latae sententiae, ut pretendebat dicta fideiconmissaria, sed a die iudicalis interpellationis; N. Bas et Galcerán, Theatrum iurisprudentiae..., part. 1, cap. 60..., núm. 107:.,., habendi vidua tenutam in subsidium bonorum liberorum in bonis fideicommisso subiectis ascendentium, non faciet fructus suos à die finiti anni luctus, sed à die petitionis....

${ }^{57}$ FONTANELla, J.P.: De pactis nuptialibus....., vol. 2, claus. 7, glos. 3, part. 5, núm. 34.

38 BAS Y GALCERAN, N.: Theatrum iurisprudentiac..., part. 1, cap. 60, núm. 108: quia ius viduitatis in Aragonia, valde simile tenutae nostri Regni, datur non solum in bonis mariti intra Aragoniae Regnum existentibus, sed etiam in bonis sitis in Regnis exteris. 
rante dicho año, los herederos de aquél hubiesen enajenado y que se hallan en poder de terceros poseedores. No tiene la mujer tenutaria la facultad de hacer suyos los frutos de aquellos bienes de los cuales tampoco pueden los herederos disponer $y$, esto es, porque se considera que la viuda no va a tener mejores condiciones que los hijos u otros sucesores. Según León, los herederos no pueden hacer suyos los frutos de aquellos bienes que se encuentran sujetos a fidecomiso cuando la posesión de los mismos se transfiere al fidecomisario, pues son para éste todos los beneficios y utilidades provenientes de dichos bienes ya que es quien los sustenta $a^{59}$. La ley en estos casos establece que el fidecomiso se restituya al fidecomisario y que éste posea los frutos de los bienes de aquél inmediatamente.

Se pueden distinguir las siguientes situaciones en relación a los bienes sobre los que no puede recaer la tenuta:

En primer lugar, cuando es el propio marido, aún vivo, quien enajena, vende o dona dichos bienes. Aunque el esposo se hubiese reservado para sí derecho de usufructo sobre los mismos, la viuda no tiene derechotenutario sobre ellos.

En segundo lugar, cuando los herederos, con el fin de saldar las deudas hereditarias, enajenan bienes sin que haya fraude alguno y por justo precio. No tiene la viuda derecho de tenuta, si la enajenación se hace para poder pagar un crédito que es anterior y más privilegiado que la dote. Tampoco lo tendrá si es menos privilegiado, pues los bienes están legítimamente fuera de la herencia para satisfacer deudas de ésta y aunque la mujer tenga acción hipotecaria para exigir el pago de su exovar, esta acción no es suficiente para que se le otorgue dicho derecho ${ }^{60}$.

$\mathrm{Y}$, en tercer lugar, tampoco tiene tenuta sobre los bienes de su suegro aunque éste haya consentido el matrimonio y haya estado presente y autorizado el contrato matrimonial ${ }^{61}$.

Los herederos no pueden librarse en tanto no hayan pagado a la viuda el exovar y el creix íntegramente. La cuestión es de qué bienes se puede pagar si todos ellos están sujetos a dicho derecho. La doctrina en este punto está dividida, ya que frente a unos autores que entienden que no se pueden vender los bienes

59 LEÓN, F.J.: Decisiones sacrae...., vol. 2, decis. 123, núms. 12 y 13: uxor tenutaria non potest facere fructus suos earum rerum, quarum baeres non faceret, ne sit melioris conditionis uxor, quam filius, aut alius baeres.... sed baeres non faceret suos fructus bonorum in fideicommisso recadentium, quia ubi rerum dominium translatum fuit in fideicommissarium.

so BAS Y GALCERÁN, N.: Theatrum izrisprudentiae..., part. 1, cap. 60, núm. 109: aut alienatio facta fuit pro solvendo credito priori in bypotheca, et magis privilegiato, quam dos, et in boc casu non erit danda tenuta viduae in bonis alienatis.... Si vero alienatio facta reperiatur pro satisfactione crediti minus privilegiati, quam dos, .....licet actione bypotecaria vidua agens pro dotis exactione, possit baec bona a tertiis possessoribus ratione anterioris bypotbecae avocare, non poterit babere tenutam, quia legitimè posita sunt extra viri haereditatem pro satisfaciendis debitis baereditariis, et bypoteca sola non suffict ad obtinendam tenutam.

61 BAS Y GALCERÁN, N.: Theatrum iurisprudentiae..., part. 1, cap. 60: quando de consensu suo filius matrimonium contraxit praesente illo, et interviniente, et authorante in matrimonii contractu, ut diximus, tamen non datur viduat tenuta in bonis saceri, licet ex illis possit solvi de dote, et augmento. 
tenutarios para satisfacer el exovar y el aumento de dote, otros consideran que los herederos si pueden enajenarlos como vía única para poder realizar dicho pago aunque la viuda sea reacia, pues al deudor se le debe permitir vender cuando el precio que va a obtener va a ser suficiente para satisfacer el crédito, además que de aquélla puede instar la venta de los bienes que sean necesarios para que se le pague. Si son bienes muebles, la mujer puede asistir a la venta y, o bien puede cobrar directamente del comprador, o bien el heredero prestará caución o depositará el valor de la enajenación. Si son inmuebles, se venden bajo la condición de que el comprador entregue el precio a la viuda o lo deposi$t^{62}$. La razón por la que se permite la venta de los bienes sobre los que recae el derecho de tenuta es porque el mismo se establece para que la mujer pueda recuperar más fácilmente su dote y creix, pues aquél constituye una vía para compeler a los herederos al pago, por lo que el precio obtenido de la enajenación debe darse a la viuda para que satisfaga su crédito y no a otras personas acreedoras. Además con esto no se causa ningún perjuicio o daño a aquélla, pues se le paga su dote, no sufriendo ninguna pérdida en su patrimonio por el hecho de que la tenuta cese. Esta cuestión queda patente en la práctica judicial ya que la mujer, que posee en virtud de tenuta todos los bienes de su marido premuerto, no puede negarse a recibir de los herederos de su esposo lo que se le debe, de la misma forma que tampoco puede hacerlo ningún acreedor cuando el deudor pretende pagarle su crédito. Los herederos si disponen de bienes para ello, pueden subastarlos durante el plazo de treinta días y con el precio obtenido por los mismos pagar el exovar y aumento de dote ${ }^{63}$.

Si bien, hay límite legal ya que, en los fueros, se prohibe a los herederos tocar o administrar los bienes del difunto así como poseer los mismos hasta que a la mujer no se le pague la dote y el creix ${ }^{64}$.

Sin embargo, no existe impedimento para que los herederos promuevan y realicen la enajenación de los bienes tenutarios pues es a ellos a quienes corresponde el dominio de los mismos y, por tanto, el ius alienandi, mientras que la mujer tenutaria sólamente tiene su usufructo, y no tiene otro derecho que el de concurrir a la venta de los bienes para poder cobrar su crédito con el precio

62 Fontanelua, J.P.: De pactis nuptialibws...., vol.2, claus. 7 , glos. 3, part. 9, núms. 13 y 14: si sunt mobilia, ea solent vendi in encantu publico, ibi assistere poterit mulier, vel alia persona receptura pecunias, quae prosedent ex venditione, vel si non vult assistere, praestezur sibi cautio,... vel fiat deporitum in tabula..... si sunt immobilia, subbastantur estiam in encantu publico, cum boc quod emptor solvat mulieri ex pretio usque od concurrentem quantitatem sui crediti, yel deponat in tabula.

63 A.R.V, Real Audiencia, Pracesos de Madrid, 1611, exped. 668, letra. P: per que com per furs de este regne ..... sia introdubida la forma en que les execusions, se ba de tenir que es que la cosa offerta sia subastada per temps de trenta dies y que sia venuda a daquell que mes ydonara... y per ser tal lo stil y costum de les corts, el qual se ba de observar com a lley.

44 Fori..., 5.5.8: lo marit dona e per lo fur... se dispon que lo fill ni altre bereu a qui pertanyga la beretat del marit no puixa algána cosa tocar ni administrar ninguns bêns del dit difunt ni entrat en la possessio de aquells béns que foren del marit... entro que la muller sia pagada del exovar e de la donasio per núbsies y de les altres uses que a la muller; A.R. Real Audiencia, proceso de Madrid, exped. 124, fol. 10 
obtenido. En este sentido, en las Cortes de 1626 se establece que la viuda no puede impedir que los herederos constituyan censos, vendan o enajenen los bienes para poderle pagar su dote, debiendo el comprador o quien da el dinero entregar el precio a la viuda como pago o parte del pago de su exovar. La cuestión quedaba clara a partir de ese momento ${ }^{65}$.

Se puede plantear, asimismo, la cuestión de si los herederos pueden vender bienes de la herencia para pagar un legado hecho por el testador en perjuicio de la viuda cuya dote no se le ha devuelto. En la Real Audiencia se dictó una sentencia el día 21 octubre de 1595 en la cual se permitía la venta de ciertos bienes recayentes en la herencia, sobre los cuales la viuda del testador tenía la tenuta al no habérsele restituído el exovar; contra la misma la tenutaria interpuso suplicación. La parte adversaria alegó que dichos bienes, por razón de la venta, ya no pertenecían a la herencia y, por consiguiente, la viuda no tenía ningún derecho sobre ellos, añadiendo, además, que si con dicha resolución no hubiese sido satisfecho el crédito, la mujer tenutaria hubiera tenido que pagarlo de los bienes de la tenuta. La Real Audiencia resolvió que los legados que el testador pueda dejar en el testamento no pueden ni deben perjudicar a la viuda en el disfrute de su derecho de tenuta ${ }^{66}$.

A instancia de los tres brazos se solicitó que se permitiera que los herederos o sucesores del marido pudieran durante este derecho constituir censos sobre los bienes en los que recaía con el fin de poder pagar a la viuda su tenuta con el dinero obtenido de dichos censales, ya que lo contrario causaría un grave perjuicio a aquéllos. En numerosas ocasiones los herederos o sucesores del marido no pueden pagar el exovar por no disponer de los títulos correspondientes a los bienes del difunto marido para poder así constituir dichos censales, pues las viudas con frecuencia rehúsan mostrarlos para este fin, encontrándose aquéllos imposibilitados para realizar el pago si no tienen dinero en efectivo o no hay censales de terceras personas sobre los bienes poseídos por el esposo premuerto ${ }^{67}$. Se estableció que la viuda tenutaria tenía la obligación de poner en poder de la Corte todos los títulos necesarios que tuviera de los bienes del marido

6s Furs y actes de Corts, fets $y$ otorgats, Cortes de 1626, Fur. 26, fol.12: nils puga impedir lo carregar, vendre, o alienar dits bens a terceres persones pera ferli dit pagament cumplidament de tota la dita sua dos, ab tal empero gue les dites vendes, alienacions o carregament de censals se bajen de fer y fermar respectivament per obs de pagar la dita dot a la tal viuda, y que lo comprador o carregador no puga donar ni llistrar los prews als berews, o altra persona alguna, sino a la dita viuda en paga, o en part de paga de la dita sua dos

66 A.RV, Real Audiencia, pracesos segunda parte, 1596, exped. 408: qui per lo Virrey y Real Audiensia de Valencia es estada donada e publicada certa sentensia eo decretum de vendendo fet e provebit de certs bens recabents en la berincia de ..... marit de dona... en las quals li estava adjudicada la tenuta per no ser estada pagada de son dot en favor de dona. Se resolvió: legata facta per testatorem, iuxta foror dicti regni VaLentiae, solvi non passunt nec debeant impraeiuditium.

67 Furs $y$ actes de Corts fets $y$ otorgats, Cortes 1626, Fur. 100, fol. 21: sia servit provehir y manar que los bereus o successors dels béns del marit, puguen durant la tenuta, fermar carregament o carregaments de sensal sobre los dits béns per obs de pagar a la viuda la dot, ab lo diner comptant del prek dels tals censals, ab que lo dit preu no puga servir pera altra cosa algúna. 
premuerto para que el heredero o sucesor pudiera pagarle su exovar mediante la constitución de censo o a través de cualquier otro medio. Como se ve, la rigidez fue mitigada por la interpretación doctrinal, así como por las cortes.

Cuando el marido responde de la restitución de la dote con un bien determinado, esto es, ésta se garantiza con una expresa obligación, se plantea si la viuda sólamente tiene derecho de tenuta sobre dicho bien o, por el contrario, sobre todos los que el marido posee al tiempo de su muerte. En el reino, la mujer tiene la tenuta sobre todos los bienes, pues así lo establecen los propios Furs y la doctrina, ya que lo contrario iría contra la propia esencia de la dote, pues un acuerdo privado entre los contrayentes no puede ir contra el interés social que existe en proteger los exovars de las mujeres.

Todo beneficio procedente del marido lo pierde la viuda si contrae segundas nupcias durante el any de plor o comete adulterio durante o después de dicho año, pero esto no afecta al derecho de tenuta por no tener tal carácter ya que éste la mujer lo disfruta por no habérsele restituído el exovar o pagado el creix y los fueros únicamente se refieren a los beneficios que aquélla obtiene del esposo y que pierde en los supuestos anteriormente mencionados ${ }^{68}$. La doctrina da una interpretación más favorable para la tenuta que la establecida en los fueros.

La tenuta se pierde, en primer lugar, cuando la mujer no hace todo lo necesario para que el exovar y creix se le paguen, prolongando el disfrute de este derecho maliciosamente o de un modo innecesario. Esto tiene lugar cuando en la herencia del marido hay bienes suficientes para que se le satisfaga su crédito dotal y permite que los mismos se apliquen a otras deudas.

En segundo lugar, si los herederos le restituyen íntegramente la dote y el creix, la viuda cesa inmediatamente en la posesión y usufructo de los bienes del marido que hasta entonces tenía, volviendo estos derechos ipso iure a aquéllos.

En tercer lugar, cuando la mujer es heredera del marido y acepta la herencia sin beneficio de inventario. En este caso, aunque ésta pida restituirse la dote como heredera que es de su marido y se tengan que valorar por los expertos de la corte de justicia los bienes que, en tal concepto, se le transportan, no puede disfrutar del derecho de tenuta ya que en realidad le pertenecen todos los bienes que recaen en dicha herencia y, por tanto, hay una confusión de patrimonios. En el siguiente pleito se ve con nitidez esta situación ${ }^{69}$.

6s Fori....., 5.2.6: la muller no pusque pendre marit dins an any pus quel marit era mort, e si bo farà perda qualque cosa per donació per núpcies o per benefici del marit bac..; Fori...., 5.2.8. si algúna fembra, après la mon del marit seu dins un any, o encara après lany compeant del dia de la mort del marit, farà fornicatio o adulteri. perda lasufruyt el violari, e totes les altres coses que baura baudes de benefici del marit.

69 A.R.V, Justicia Civil, serie iudiciari, 1691, signat. 2.293, mano cercera: se condena a Maria Carbonell a tenerse que restituir y pagarse asi misma en nombre de heredera de Felix Vila, su marido, de una parte 1.000 libras de la dote y, de otra parte, 500 libras por el creix, dando faculcad a dicha Maria Carbonell para que pueda transportarse asi misma bienes muebles y sitos que recaen en 
En la alegación jurídica realizada en el litigio que tiene lugar entre don Baltasar Escudero, heredero de Doña Inés María de Lima, marquesa de Llanera, con el Marqués de Llanera, en el que se pide que se reforme y mejore las sentencias que negaron la tenuta, se afirma que la marquesa al ser heredera no puede ser parte activa y pasiva en el litigio, pues ello implica una confusión de acciones y, por tanto, con la adición de la herencia debe darse por pagada. Pero ocurre que la marquesa hace inventario de los bienes libres hereditarios, en el cual no aparecen objetos valiosos o de gran valor, por lo que se estima que ello no daña a su derecho de tenuta ya que los bienes no equivalen más que a una décima parte de la dote aportada, además de que se trata de cosas muebles que servando servari non possunt. Por esto se alega que, en dicho caso, no se puede aplicar el criterio de paga presunta para excluir el derecho tenutario a la viuda heredera a beneficio de inventario. En este caso, al no haber bienes libres, hay que hacer efectivo el derecho en los bienes vinculados por ascendiente ${ }^{70}$.

En cuarto lugar, cuando la dote consiste totalmente en bienes inmuebles pues en este caso debe restituirse inmediatamente tras la muerte del esposo, sin tener que esperar a que transcurra el any de plor. Además, algunos autores entienden que si en el caudal hereditario hay alhajas de oro y plata, ganado o efectos muebles suficientes para pagar la dote, la mujer podrá promover su venta en vez de la tenuta, si los herederos no le restituyen el exovar.

\section{EFECTOS}

La tenuta, como ya se ha dicho, se inicia al día siguiente de la finalización del año de luto, pero en relación a los bienes sujetos a fidecomiso, hay que diferenciar dos situaciones. Primeta, si la viuda ya posee los bienes sujetos a vínculo, en cuyo caso los frutos los hace suyos una vez finalizado el any de plor. Segunda, cuando no los posee, en cuyo caso debe poseer los bienes libres y hacer suyos los frutos de éstos si son suficientes y si no lo son, poseerá los vinculados pero sólo hará suyos los frutos desde que realiza la petición ${ }^{71}$.

dicha herencia, precediendo estima por los expertos de la corte de justicia, excepto la casa que ya fue estimada.

70 B. Universitaria, Varios, 237-14, argumento jurídico por Don Baltasar Escudero y Campo, heredero de la marquesa de Llanera y condesa de Olocau, Doña Inés Maria de Lima, Silva y Abreu, en los autos de liquidación de frutos con el marqués de Llanera sobre que se mejoren y reformen las sentencias que negaron la tenuta y teneo de dicho marquesado.

$"$ TrOBAT, J.B.: de efectibus immemorialis...., tít. S, quaest.9, cap. 60 de restitutione dotis at aug. menti...., núms. 122 y 123 : si vidua possidebat vincula fideicommisso subiecta, faciat fructus stos statim finito anno lucto; si vero non passidebat, consequitur ab ea die fructus bonorum liberorum, etiam si eo ab baeredibus possideatur: respectu vero bonorum in fideicommisso recadeantium, tantum consequitur eorum fructus, a die petitionis intentatae contra dicta bona possidentem; BAS Y GALCERÁN, N.: Theatrum iurisprudentiae......, part. 1, cap. 60, núm. 107: tamen quando tenuta praetenditur in bonis fideicommisso subiectis, non debentur fructus ratione tenutae viduae, neque illos facit swos a die finiti anni luctus, sed a die tantum petitionis. 
La viuda tiene que solicitar ante el justicia que se declare que le compete el derecho de tenuta sobre todos los bienes que poseía su marido difunto, así como que se le restituyan todos los frutos producidos por dichos bienes desde que finalizó el any de plor ${ }^{72}$.

Comprobada que la dote fue aportada y que no se ha devuelto la misma, así como que el creix correspondiente no se ha pagado, se resolverá reconociendo dicho derecho en favor de la mujer viuda y condenando a los herederos del esposo a la restitución de los frutos producidos desde el día en que concluyó el año de duelo ${ }^{73}$.

Reconocido su derecho de tenuta en los bienes de su marido premuerto, la viuda puede pedir ante los tribunales que, además de que se le ponga en posesión de dichos bienes, se expida mandato para que todos los deudores de la herencia de su esposo la tengan y la reputen como tenutaria y, en su caso, le paguen las prestaciones anuales que, como censalistas o que por otras causas, están obligados a abonar ${ }^{74}$. En las dos sentencias dictadas a favor de la marquesa viuda de la Casta se declaraba que debía ser puesta en posesión de los bienes que recaían en los mayorazgos de Alaquás y Bolbayt y sus agregados, con la

72 A.R.V, Real Audiencia, procesos tercera parte apéndice, 1636, exped. 7.545; Eufemia del Castellar, viuda supplicant, meliore modo que potest dir, que ab cartes núbsials rebudes per Vicent Barba, notari, en tres de agost del any 1628, collocantse en matrimoni la dita supplicant ab lo qondam Joan Batiste 2 llcoser, ciutada de la Vila de LLiria, li portà y constitui en dot dos milia litures en lo modo y forma contenguts en els dites cartes nubsials de que fa presentació, si, et in quantum. E com señor excelentissim lo dit Joan Batiste Alcoser baja molt temps que es mort sens que jamés a la dita supplicant se li baja fet pagament intra nec extra annum lactus y per conseguent a foro li competeix la tenuta de tots los bens de la berencia del dit Joan Batiste Alcoser. Pertant la dita supplicant fentseli et inquantum de la publicasio del altim testament del dit Joan Batiste Alcoser... supplica sia mantat declarar que la dita sapplicant li competix la tenuta en tots los béns del dit Joan Batiste Alcoser $y$ que tots los fruits a die finiti anni luctus son propris de la de la dita supplicant, condemnant al curador dels fill y bereks del dit Joan Batiste Alcoser en restitubir ditos fruits...

73 A.R.V, Real Audiencia, procesos tercera parte apéndice, 1636, exped. 7.545: pronuntiamus, sententiamus et declaramus competere tenutam dictam.... omnium bonorum dicti sui iuxta fori forman et consequenter expediri debere facet com presenti expediri mandamus mandata per illam supplicata in memorata supplicatione...; Gobernación, signat. 3.872, año 1680, proceso entre Luisa Primo, viuda de Juan Gomar, con José Gomar, dictándose la sentencia el 23 marzo de 1680: pronuntiam sententiam y declaram la dita demanda de tenuta restar justificada .... competinle a la dita Laysa Primo y de Gomar, viuda, la tenuta de tots Los béns y drats que sempore mortis possebia dit Jaan Gomar, condempnant segons que ab la present nostra sentencia condempnan al dit Juseph Gomar en nom de bereu iure successionis ab intertato de Joan Gomar, son fill, en baver de restituir y entregar infra decem causa cognita a la dita Laysa Primo tots los béns y dress que tempo$r$ mortis possebia dit Joan Gomar una cum fructibus a die finitis anni luctus, pera que possebixca aquells la dita Laysa Primo y fasa los fruits seus desde el dia que fini lo any de plor fins tant estiga ab integro pagada de dita dot y creix...; Real Audiencia, sentencia 12 diciembre 1615, Alrreus, caja 77, exped. 8. 538.

74 A.R.V, Real Audiencia, pracesas tercera parte apéndice, 1636, exped. 7.545: Exfemia del Castellar $y$ de Alcoser, viuda, supplicant meliori modo que potest dis que per execusió de la real sentencia ab la qual $l i$ fonch adjudicada la tenuta de tots los béns de la berencia del quondam Joan Batiste Alcoser fonch despacbada comisió al escrivá de la causa pera que posara en possersió a la dita supplicant de tots los béns de la dita herencia $y$ aixi mateix pera que manara a tots los deutors sensalisfes $y$ de altres annwals prestacions de dita berencia tinguen $y$ reputen a la dita supplicant per tenutaria de dits béns $y$ li paguen en los deguts terminis 
facultad de hacer suyos los frutos, sin tenerlos que imputar a la fuente principal hasta que no estuviese enteramente pagada ${ }^{75}$.

Situaciones especiales en que la viuda se puede encontrar tras habérsele restituido el exovar son: en primer lugar, cuando no se le ha pagado el creix. Se estableció en las Cortes de 1626, que el creix se debía pagar mediante cargamento de censal, a razón de un sou por libra durante toda la vida de la mujer, de manera que si dichas pensiones, que deben pagarse puntualmente, se dejan de abonar durante dos años, tras dos interpelaciones extrajudiciales, la viuda tiene ipso foro la tenuta con el privilegio de hacer suyos los frutos como si no se le hubiese pagado la dote ni el creix ${ }^{76}$.

Y en segundo lugar, si habiéndosele pagado tanto el exovar como el creix, tiene contra los bienes de la herencia de su esposo otros créditos, la viuda puede retener los bienes tenutarios hasta que los mismos le sean enteramente satisfechos, aunque sin la facultad de hacer suyos los frutos, ya que los mismos deben imputarse a la herencia ${ }^{77}$.

La tenuta se configura como un derecho de posesión y de usufructo, de ahí que la viuda tenga las mismas obligaciones que las del usufructuario, excepto la de prestar fianza ${ }^{78}$. Así, debe cumplir con las obligaciones de alimentos que a favor de los hijos y de otras personas tenía el difunto marido, satisfacer las cargas hereditarias módicas y comunes, realizar los gastos necesarios para la conservación y reparación de los bienes, cuidar con diligencia dichos bienes y restituir los bienes sujetos a tenuta cuando la dote y el creix se le hayan pagado. Por el contratio, no debe soportar los gastos que ocasione la defensa de los bienes hereditarios ya que los mismos son de cuenta de los herederos y si lo ha hecho puede cobrarlos. Además, no tiene que prestar ninguna garantía sobre los bienes que posee del marido en virtud de este derecho, ya que se trata de un usufructo legal sin la carga de tener que dar caución ${ }^{79}$.

La capacidad que tiene la viuda de hacer suyos los frutos no la pierde aunque falte una mínima parte por pagar del exovar o del aumento de dote y su

75 Biblioteca Universitaria, Varios, signat.67, núm. 21.

76 Furs $y$ actes de Corts fets $y$ otorgats, Cortes 1.626, Fur. 110 , fol. 22.

7 BAS Y GALCERÁN, N.: Theatrum ivrispnudentiae ....,part. 1, cap. 60, núm. 115: si viuda fuerit soluta de dote et augmento, aut per depositum, aut aliter, babebit adbuc retentionem bonorum tenutae pro caeteris creditis, quate contra mariti baereditatem babet, quousque satisfacta fuerit, sed absque facultati faciendi fructus stos; FONTANELLA, J.P.: De pactis nuptialibus...., vol. 2, claus. 7, glos. 3, part. 6, núm. 47: sed si alia in baereditate muller baberet credita, veluti quia aliqua solvisset pro baereditate, quae ad eam non spectabant, vel alias, an facta satisfactione mulieris in dote et sponsalitio statim teneatru baereditatem restitue$r e$, an vero retentionem babeat pro dictis creditis... quod licet por aliis creditis non possit mulier facere fructus suos, cum pro soludote et sponsalitio beneficia boc constitutio concedad, verum retentionem sine dubio babet donec in dictis creditis sit ei satisfactum

78 FONTANELl.A, J.P.: De pactis nuptialibus...., vol. 2, claus. 7, glos. 3, part. 2, núrns. 50 y 77.

79 LISSA, A.C.: Tyracinium iurisprudentiat....., lib. 2, tít. 4 de susfrutu.... se in tenuta soluto matrimonio, iuxta leges Cathaloniae et Valentiae, viduae concedenda, sive baer consistat in rebus mobilibus, sive in rebus solo coberentibus indistincte, vidus admiti adbunc usumfructum legalem absque onere satisolationes.

Hispania, LX/2, núm. 205 (2000) 453-478 
derecho no se ve disminuído en nada por cualquier cantidad que reciba de los herederos del marido o de cualquier otra persona en pago del exovar; incluso, si se le ha devuelto la dote y el creix no se le ha dado, seguirá poseyendo los bienes del marido premuerto, tal y como lo recogen los propios fueros ${ }^{80}$.Y en la práctica judicial de esta época queda reflejado el hecho de que la viuda no pierde su derecho, aunque haya cobrado alguna parte de su dote o haya recibido íntegramente ésta y le falte percibir el creix ${ }^{81}$.

Según Trullench, si alguna parte de la dote se paga y la otra no, la mujer hace todos los frutos suyos como si nada se le hubiese pagado, excepto que, por la parte cobrada ella decida libremente no percibirlos ${ }^{82}$. En este mismo sentido se expresa Bas, el cual afirma que el derecho de tenuta puede limitarse cuando a la mujer se le entrega alguna parte del crédito dotal y ésta certifica que, por la parte que cobra, pierde su derecho tenutario, en cuyo caso, sólo percibe los frutos correspondientes a la parte de la dote y creix que resta por pagar ${ }^{33}$.

En el pleito que tiene entablado Josefa María Berenguer, viuda de Gerardo Molina, con el doctor Francisco Molina, su cuñado ${ }^{84}$, alega aquélla que le corresponde la posesión y tenuta foral de los bienes que habían al tiempo de la

so Fori..., 5.5.10: Per ço sie declarat, e provebit que, si aprés mort dels marits, lo beren d'ells no satisfarà a la muller del dote e creix que ba en los béns de son marit e per gô, segons fur dins l'any del plor li serì tachada provisió e apn's l'any fara los fruyts seus dels béns del mani que per bé que per los bereus, e qualsevol altres persones a la muller serà pagada alouna quantitat o part gran o poca de la dita dot, o creix, o la dita muller la baurà rebuda: per qualsevol mantera a la dita muller per la dita paga o pagues no sia disminuidda alcana cosa de la dita provisio ni dels dits fruyts, ans baja entregament e complida la dita provisio, e fruyts cascuna cosa en son temps per poca quantitat o part que li nmanuga a pagar, o part de la dit dot e creix: fins que complidament e ab acabament sia pagada e satisfyta de la dita dot e creix; BAS Y GALCERín, N.: Theatrum iurisprudentiae.. part. 1, cap. 60, núm. 104: babebit vituda tenutam foralem bonorum cum facultate faciendi fructus stos.... nam etiam si aliqua pars dotis saluta fuerit, aut integra dos, sed non omne dotis augmentun, aute comverso, et aliqua pars etiam minima dotis, aut augmenti restet solvi, dabitur, et conservabitur viduat tenuta...

81 A.R.V, Real Audiencia, procesos de Madrid, 1611, exped. 668: que tots los béns recabents en la dita berengia del dit quondam Cristofol Martinez de Vera, cavaller, señor del llach de Busot, desde el dia de la sua mont fins lo dia de buy son estats y están en poder de la dita Maria Magdalena Pasqual, viuda de aquell, per que de part de aquell se li feu pagament de dos y los demés sels ba retengut en son poder com a tenutaria per no baverseli pagat lo creix.

${ }_{82}$ Truluench, J. G.: Opus morale, sive in ........, lib. 7, cap. 9, dub. 14, núm. 12: si aliqua pars si soluta, et alia non, possit absolute fructus suos facere, ac si nibil esset solutum, nisi ipsa fructus pro parte soluta libere condonavit.

83 BAS ET GaLCERÁN, N.: Theatrum iurisprudentiox...., part. 1, cap. 60. núm. 104. fol.582: .certificata fuerit, quod accipiendo partem illam, amittere debet tenutat partem conreppondentem parti dotis solutae, et augmenti, nem boc in casu non faciet frutus suos, nisi prowrata illius partis dotis, et augmenti, quate remanet solvi.

84 B. Universitaria, alegación jurídica, signat. R-2/362, núm. 32: informe en hecho y derecho por Josefa María Berenguer, viuda de Gerardo Molina, vecina de la Villa de Onil, en los rres pleitos con el doctor Francisco Molina su cuñado, vecino de la misma villa. El primero sobre que a dicha Josefa María Berenguer se le reintegre en la posesión de los bienes del dicho Gerardo Molina, su marido, por el derecho de tenuta foral de su dote, eo por el de sociedad, o pagarle 5.875 libras, 6 sueld. 8 din. con intereses. El segundo sobre el que se le den ropas usuales y bienes exrradorales. El tercero, sobre que se le absuelva de los daños y perjuicios que pretende el dicha doctor Molina su cuñado. 
muerte de su marido ya que, transcurrido el primer año de viudedad, no se le ha pagado ni la dote ni el creix y, por consiguiente, le corresponde ipso iure la posesión de dichos bienes y el disfrute de los frutos. Afirma que este derecho procede aunque se haya pagado la mayor parte del exovar y del creix, faltando solamente una mínima parte, porque en virtud del mismo se obtiene la posesión y todos los frutos producidos desde el día en que concluyó el año de luto hasta la fecha que estén totalmente pagados aquéllos.

Además, se debe reconocer este derecho tanto por los capitales debidos, como por los intereses ya que, en el presente caso, no sólo no se ha pagado el aumento de dote, ni los alimentos correspondientes al any de plor sino que, tampoco los intereses correspondientes a la dote que se ha pagado mediante depósito y es que, tal y como establece la doctrina, cuando a la viuda se le paga su exovar y creix utilizando este medio, se tiene derecho de tenuta por los créditos.

Por último, se afirma que a la viuda por la tenuta, se le debe considerar no sólo como poseedora actual y real, sino que se le tiene que conceder los remedios posesorios de tecuperar y retener, de manera que pueda frente a cualquiera que hubiera ocupado sus bienes, despojarlo de los mismos.

Concluyendo, se puede afirmar que la tenuta constituye una garantía porque se trata de un derecho cuya existencia no se debe a la viudedad de la mujer, sino que con ella se asegura la restitución dotal y el pago del creix. Mediante éste, la esposa pasa a poseer todos los bienes del marido premuerto con la facultad de hacer suyos los frutos, mientras no se le restituya la dote y se le pague el aumento. Se caracteriza por no prescribir y por no poder privarse, expresa o tácitamente, del mismo a la viuda ya que no lo obtiene por razón del esposo, sino por establecerlo así la ley y por razón del exovar no devuelto y del creix no pagado. Nace cuando el año de luto concluye y el término de finalización depende de cuando los herederos del marido restituyan y paguen, de modo que si, disuelto el matrimonio, éstos devuelven inmediatamente la dote y pagan el aumento dotal, la tenuta no es que cesa, es que nunca llega a nacer. 